\title{
Protocol: optimised electrophyiological analysis of intact guard cells from Arabidopsis
}

\author{
Zhong-Hua Chen ${ }^{1,2}$, Cornelia Eisenach ${ }^{1}$, Xin-Qin Xu ${ }^{1}$, Adrian Hills ${ }^{1}$ and Michael R Blatt ${ }^{1 *}$
}

\begin{abstract}
Genetic resources available for Arabidopsis thaliana make this species particularly attractive as a model for molecular genetic studies of guard cell homeostasis, transport and signalling, but this facility is not matched by accessible tools for quantitative analysis of transport in the intact cell. We have developed a reliable set of procedures for voltage clamp analysis of guard cells from Arabidopsis leaves. These procedures greatly simplify electrophysiological recordings, extending the duration of measurements and scope for analysis of the predominant $\mathrm{K}^{+}$and anion channels of intact stomatal guard cells to that achieved previously in work with Vicia and tobacco guard cells.
\end{abstract}

Keywords: Microelectrode, $\mathrm{K}^{+}$channel (voltage-gated), $\mathrm{Cl}^{-}$channel, Voltage-gated, Membrane conductance, Mutant analysis, Arabidopsis

\section{Introduction}

Stomata are pores, commonly found in the epidermis of leaves, and are surrounded by a pair of specialised cells known as guard cells. Guard cells regulate the size of the stomatal pore to balance the exchange $\mathrm{CO}_{2}$ for photosynthesis with the need to conserve water [1]. The acquisition of stomata and the leaf cuticle are considered to be key elements in the evolution of advanced terrestrial plants [2] allowing plants to inhabit different and often fluctuating environments while controlling water content. Stomatal pores typically occupy less than $5 \%$ of the leaf surface, but they provide for over $90 \%$ of the $\mathrm{CO}_{2}$ entering the leaf and over $70 \%$ of water loss from the plant as a whole [3]. Guard cells respond to a number of well-defined signals - including hormones, light and atmospheric $\mathrm{CO}_{2}$ concentration - integrating these signals to regulate stomatal aperture $[4,5]$.

In the past few decades, the combination of physiological and molecular biological methods in the model plant Arabidopsis thaliana has greatly advanced our understanding of stomata [1,4-7]. Among these, voltage clamp methods have proven powerful in connecting the molecular and physiological frameworks in an understanding of stomatal function. The voltage clamp itself

\footnotetext{
*Correspondence: Michael.Blatt@glasgow.ac.uk

'Laboratory of Plant Physiology and Biophysics, Institute of Molecular, Cell and Systems Biology, University of Glasgow, Glasgow G12 8QQ, UK Full list of author information is available at the end of the article
}

lies at the core of a toolchest of techniques and provides the essential utility to bring the driving force of membrane voltage under experimental control. By so doing, it enables the dissection, identification and monitoring of ionic currents carried by individual ion transporters ATP-dependent pumps, ion-coupled carriers and ion channels - across biological membranes [8]. Classic voltage clamp methods rely on impalements with two microelectrodes (or a single microelectrode with two separate barrels) that are used to measure membrane voltage and to pass current for voltage clamping, respectively $[8,9]$. Because a defined spatial geometry is essential for quantifying current spread under clamp conditions [8-10], these methods have proven highly successful for work primarily on a small number of single-celled species as well as cell types that are easily isolated from their surrounding tissues [11-17].

Since its wider introduction in the 1980's [18,19], the patch clamp variant of the voltage clamp has been widely used in studies of plant ion channels $[8,20]$. The patch clamp offers a number of advantages for work on plant cells, the most important being the facility for electrical recordings from single cells isolated from almost any surrounding tissue, thereby avoiding the difficulties of electrical coupling via plasmodesmata between cells in situ [21]. It also presents some difficulties. For patch clamp recordings from plant cells it is essential to remove the cell wall, commonly by enzymatic digestion, 
and to stabilise the protoplast against osmotic swelling in the absence of turgor. Both manipulations affect the underlying homeostatic properties of the cells and must influence their physiological behaviour [22,23]. Additionally, obtaining electrically and mechanically robust seals between the patch electrode and protoplast, and retaining stable measurements without significant "rundown" of currents over long periods of time are often challenging $[20,24]$.

By contrast with many plant cell types [but see Chen et al. [15]], guard cells at maturity do not retain electrical connections with their neighbours [11,25]. They are easily separated by mechanical peeling of leaves [1] and recovered intact with their cell wall within the monolayer of epidermal cells. These features greatly simplify their handling for voltage clamp recordings and analysis, avoiding the need to isolate protoplasts and the technical challenges of the patch clamp. Despite the obvious advantages, only a very few studies [26-28] have made use of microelectrode impalements and classic voltage clamp methods with intact Arabidopsis guard cells. A major difficulty in this case has been to obtain reliable measurements over 20-30 min or more, time periods long enough for physiological and pharmacological studies with single cells. Thus, many researchers have relied on statistical approaches in patch recordings from populations of guard cell protoplasts, often without an internal reference for comparisons; simply put, impalement methods have not offered significant benefits in overcoming the problem of 'rundown' in channel activities common to patch clamp recording $[20,24]$.

We have revisited the problems of voltage clamp recording from intact Arabidopsis guard cells and offer here a few simple procedures that enable classic, two-electrode voltage clamp recordings. Included with this protocol are summaries of results demonstrating its utility in characterising the major ion channel currents and their stability over time periods of one hour or more. The impalement approach greatly simplifies experimental access to these currents and enables physiological studies to be carried out on a cell-bycell basis.

\section{Materials}

\section{Plant materials}

- Arabidopsis thaliana. For purposes of demonstration, we included with wild-type (Col0) the nitrate reductase-null mutant nia1-1/nia2-5 (nia1nia2) [29], the ABA-receptor quadruple mutant pyr1/pyl1/pyl2/pyl4 (QC3) [30], the vesicletrafficking mutant syp121 (=syr1/pen1) and its complementation with SYP121 [31,32], the dehydroascorbate reductase mutant dhar1-3 [33], and the $\mathrm{K}^{+}$channel mutant $k c 1-2$ [31].

\section{Reagents}

- $\mathrm{KCl}, \mathrm{Ca}(\mathrm{OH})_{2}, \mathrm{NaOH}, \mathrm{HCl}, \mathrm{CsCl}$, tetraethylammonium chloride (TEA-Cl), potassium acetate $\left(\mathrm{K}^{+}-\mathrm{Ac}\right)$, and 2-(N-morpholino)ethanesulfonic acid (MES) analytical grade.

- Opening Buffer (OB) for pretreating the stomatal guard cells, comprising $50 \mathrm{mM} \mathrm{KCl}$ and $10 \mathrm{mM}$ MES, titrated to its $\mathrm{pH} 6.1$ with $\mathrm{NaOH}$, without added $\mathrm{Ca}^{2+}$.

- Recording Buffer 1 (RB1) for voltage clamp measurements of $\mathrm{K}^{+}$channel currents, comprising $10 \mathrm{mM} \mathrm{KCl}$ and $5 \mathrm{mM}$ MES, titrated to $\mathrm{pH} 6.1$ with $\mathrm{Ca}(\mathrm{OH})_{2}\left(\left[\mathrm{Ca}^{2+}\right]=1 \mathrm{mM}\right)$.

- Recording Buffer 2 (RB2) for voltage clamp measurements of the $\mathrm{Cl}^{-} /$anion channel currents, comprising $15 \mathrm{mM}$ TEA-Cl, $15 \mathrm{mM} \mathrm{CsCl}$ and $5 \mathrm{mM}$ MES, titrated to $\mathrm{pH} 6.1$ with $\mathrm{Ca}(\mathrm{OH})_{2}\left(\left[\mathrm{Ca}^{2+}\right]=1 \mathrm{mM}\right)$.

\section{Equipment}

- Environment-controlled growth room

- Refrigerator for stratifying seeds at $4^{\circ} \mathrm{C}$

- Narashige PD5 multi-purpose microelectrode puller or equivalent, modified for multibarrelled microelectrodes [9].

- High-impedance $\left(>10^{11} \Omega\right)$, multi-channel voltage clamp amplifiers and probes $[8,9]$

- Desktop computer and data acquisition system $[8,9]$

- Light microscope with a total magnification at least $400 \times$ or higher

- 12-volt battery for DC power to supply microscope

- Huxley-type micromanipulator with carrier (see below) incorporating light-weight micropositioner (e.g. Narishige C2-type micromanipulator)

- Faraday cage

- Anti-vibration table

- Gravity-feed system for switching between experimental solutions [9]

- Optically clear and pressure-sensitive silicone adhesive $[8,9,12]$

- Fine-tipped forceps, dressing forceps and razor blades

- Glass capillaries for double-barrelled microelectrodes [9]

- Two-ml polypropylene pipettes, silicon rubber and 0.5-mm diameter Ag wire for halfcells (see [9] and below)

\section{Protocol}

Key steps for growing Arabidopsis plants and selecting guard cells for voltage clamp

Growth history has an appreciable impact on stable voltage clamp recordings in Arabidopsis guard cells. 
1. Pretreat compost with Intercept 70WG

(Scotts, Ipswich, UK), a systemic insecticide.

2. Sow seeds onto the nutrient-rich Levington $\mathrm{F} 2+\mathrm{S} 3$ compost (Coulders, Glasgow, UK) in $60 \mathrm{~mm}$ pots covered with polyester mesh (Remnant Kings, Glasgow, UK Figure 1A) to avoid soil contact of the abaxial leaf surface and soil-borne stress factors.

3. Stratify seeds at $4^{\circ} \mathrm{C}$, once sown, for 48 hours and leave the seed to germinate under a plastic lid (>95\% RH) for one week.

4. Cultivate plants in a controlled environment growth room under long day conditions with $100 \mu \mathrm{mol} \mathrm{m} \mathrm{m}^{-2} \mathrm{~s}^{-1}$ light and a light/dark cycle of $16 \mathrm{~h} / 8 \mathrm{~h}, 22 / 18^{\circ} \mathrm{C}$, and $55 / 70 \% \mathrm{RH}$. Evenly and regularly water plants from below.

5. Transfer pots after one week to propagators. We use propagators with NITEX mesh fabric (mesh opening $200 \mu$ m diameter; Sefar, Heiden, Switzerland) over the sides of the covers to permit free air exchange while keeping out insects.

6. In preparation for experiments excise either the $5^{\text {th }}$ or $6^{\text {th }}$ true leaf of three-week-old plants; these leaves display an elliptical shape and are more serrated compared to the older leaves. NOTE: There is a correlation between stomatal responsiveness and stomatal age, the most responsive stomata often occur on leaves with higher stomatal densities, many stomatal primordia and smaller epidermal cells (Figure $1 B$ and C). Successful impalements yield similar currents under voltage clamp when recorded from guard cells of plants grown under long-and short-day conditions. Nonetheless, we favour plants grown under long days, as growth under short days gives lower stomatal densities (Figure 1D).

7. Pretreat the glass of the measuring chamber, coating it with Dow-Corning silicon prosthetic adhesive (Factor II, Tucson, USA; see [9]). NOTE: Silicon adhesive is pressure-sensitive and optically clear. Once dried, it remains useable for many weeks, even under water. However, the solvent used in the adhesive must evaporate before use or it will kill the cells.

8. Excise the epidermis of the leaf by wrapping the leaf over a finger, adaxial side down, cut into the mesophyll near the base of the mid-vein with
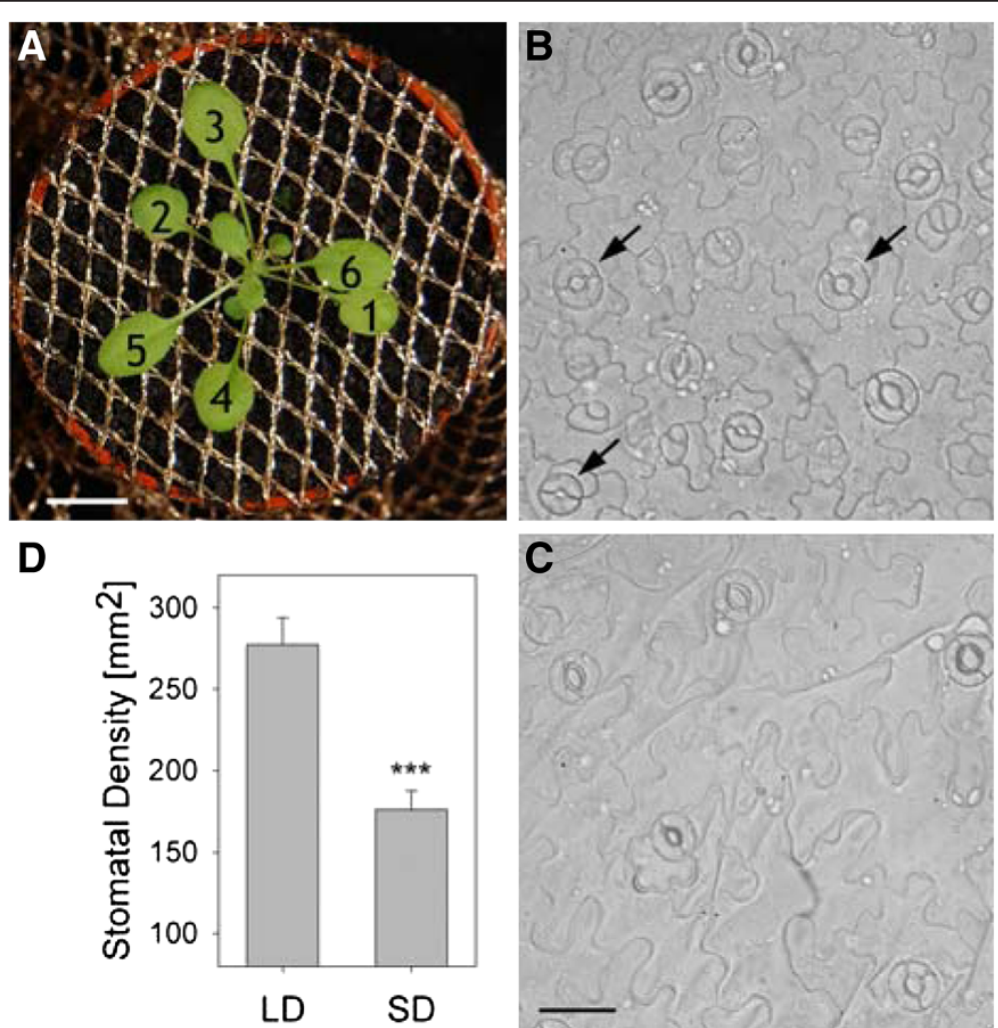

Figure 1 Growth and selection of Arabidopsis guard cells on epidermal peels. (A) Rosette of a plant after 19-d growth at the stage from which epidermal peels were taken for impalements. Plants were grown in individual flower pots, covered with a polyester mesh. True leaves are numbered in order of their appearance. Scale bar, $1 \mathrm{~cm}$. (B, C) Epidermal peels taken from plants grown under long-and short-day periods, respectively. Note the higher density of stomata and the smaller size of the epidermal cells in (B). Scale bars, $30 \mu m$. Arrows in (B) indicate examples of guard cell pairs favoured for impalement (D) Stomatal densities of plants grown under long-day (LD) and short-day (SD) ( $n=46)$. The significance level is indicated with asterisks $(P<0.01)$. 
forceps, and lift the abaxial epidermis away from the mid vein towards the leave margin. Gently replace peel against the mesophyll, keeping a gentle tension to avoid folds, then cut at the end of the peel near the leaf margin using a fresh (sharp) razor blade. NOTE: It is often easier to peel away the epidermis some minutes after excision when the leaf is less turgid, and to work from the petiole to the apex of the leaf. Ideally, epidermal peels should be free from wrinkles, folds, dirt and, once mounted, air bubbles. Successful impalements are best obtained from open stomata with young guard cells (arrows, Figure 1B), as judged by the thickness of the stomatal lip and squat shape of the guard cells.

9. Press the abaxial side of the leaf with the excised epidermal peel gently onto the prosthetic adhesive
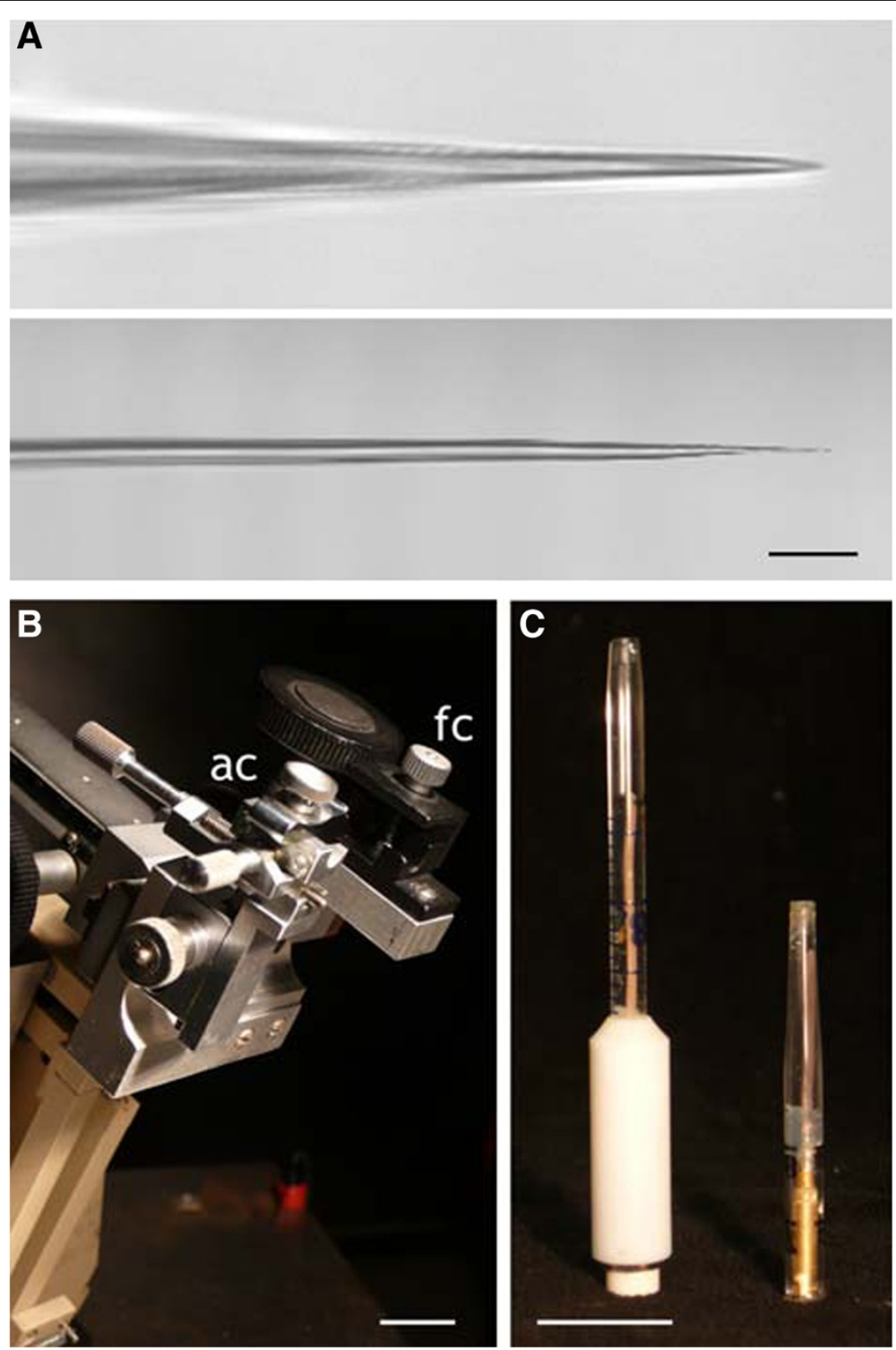

Figure 2 Mechanical improvements for Arabidopsis guard cell impalement. (A) Double-barrelled microelectrodes pulled with settings for Vicia (above) and for Arabidopsis (below), in the latter case showing a 1-1.5 taper to the final $10 \mu \mathrm{m}$ of the tip. The extreme tips of both microelectrodes are below the resolution of the light microscope. Scale bars, $10 \mu \mathrm{m}$. (B) A custom-built brace with a fixed clamp (fc) for one amplifier headstage and a second, adjustable clamp (ac) provided by a Narashige C2 micromanipulator. The entire brace is fixed to the lateral, rack-and-pinion coarse movement of a Huxley-type micromanipulator visible behind. Scale bar, $1 \mathrm{~cm}$. (C) Halfcells of the Ag|AgCl-KCl type constructed (left) using $0.5 \mathrm{~mm}$ diameter Ag wire soldered to a 2-mm diameter socket threaded in a PTFE sleeve and fitted with silicon and glass tubing, and (right) using $0.5 \mathrm{~mm}$ diameter Ag wire soldered to a 2-mm diameter socket and press-fit with a silicon plug behind the tip segment of a 2 -ml graduated polypropylene pipette tip. Scale bar, $1 \mathrm{~cm}$. When backfilled with $\mathrm{KCl}$ electrolyte, the halfcells weigh $5.5 \mathrm{~g}$ (left) and $0.6 \mathrm{~g}$ (right). For general details of halfcell construction, see [9]. 
Table 1 Effect of pretreatment with opening buffer (OB) on stomatal aperture in all Arabidopsis lines Col-0, nia1nia2, QC3, QL3, kC1-3, syp121, syp1210x, and dhar1-3

\begin{tabular}{lllllllll}
\hline \multicolumn{3}{l}{ Average of 8 lines } & Col-0 & & \multicolumn{2}{l}{ nia1nia2 } & & QC3 \\
\hline Aperture $(\boldsymbol{\mu m})$ & Control & Pretreatment & Control & Pretreatment & Control & Pretreatment & Control & Pretreatment \\
\hline I $_{k}$ experiments & $2.95 \pm 0.04(150)$ & $3.22 \pm 0.09^{*}(99)$ & $3.05 \pm 0.07(79)$ & $3.55 \pm 0.15^{* *}(39)$ & $2.41 \pm 0.11(12)$ & $2.87 \pm 0.09^{*}(58)$ & $3.12 \pm 0.09(46)$ & $3.63 \pm 0.15^{* *}(15)$ \\
Ianion $_{\text {axperiments }}$ & $2.89 \pm 0.06(84)$ & $3.48 \pm 0.09^{* *}(74)$ & $2.89 \pm 0.06(28)$ & $3.45 \pm 0.13^{* *}(30)$ & $2.47 \pm 0.11(23)$ & $3.00 \pm 0.12^{* *}(25)$ & $3.17 \pm 0.09(33)$ & $3.83 \pm 0.16^{* *}(19)$ \\
\hline
\end{tabular}

Data are means \pm SE of $(n)$ experiments.

${ }^{*} \mathrm{P}<0.05$; ${ }^{* *} \mathrm{P}<0.01$ as compared with control. Arabidopsis lines and mutants as indicated: the nitrate reductase null mutant nia1-1/nia2-5 (nia1/nia2) [58,59] and ABA-receptor quadruple mutant pyr1/pyl1/pyl2/pyl4 (QC3 and QL3) [60], the vesicle trafficking mutant syp121 (=syr1/pen1) and the syp121ox over expression line [53], the dehydroascobate reductase mutant (dhar1-3) [62], and $\mathrm{K}^{+}$channel mutant kc1-2 [53]. All lines were in the Arabidopsis Columbia-0 (Col-0) background except QL3, which was in the Landsberg (Ler) background.

NOTE: Stomatal apertures were measured in epidermal peels of young leaves from three to five weeks old Arabidopsis plants. All operations were carried out on an Axiovert 135 fitted with Nomarski Differential Interference Contrast optics and an AxioCam digital camera system (Zeiss, Jena, Germany). All measurements were conducted in continuous flowing solutions. For measurements of apertures, 8-12 stomata were selected and their images recorded at 5-min intervals for subsequent analysis using Image J v.1.42 (http://rsbweb.nih.gov/ij/). Apertures and dimensions of impaled guard cells were determined using a calibrated eyepiece micrometer and cell volumes calculated assuming a spheroid geometry.

coating of the measuring chamber glass. Remove the remaining leaf tissue and cover the epidermal peel immediately with $\mathrm{OB}$ to prevent it drying.

\section{Key steps for pulling microelectrodes}

The volume of an Arabidopsis guard cell is typically 10$15 \%$ that of Vicia and tobacco guard cells. Thus, microelectrodes with input resistances near $100 \mathrm{M} \Omega$ when filled with $200 \mathrm{mM} \mathrm{K} \mathrm{K}^{+}$-Ac, such as have been used in the past $[13,34]$, are not suitable and generally give a low rate of success and a high leak conductance with little evidence of selective transport activity.

1. Pull microelectrodes to give tip resistances of 300$500 \mathrm{M} \Omega$ when filled with $200 \mathrm{mM} \mathrm{K}^{+}$-Ac.

2. For double-barrelled microelectrodes with the higher input resistances (and correspondingly lower electrolyte leakage rates), pull double-barrelled microelectrodes, after twisting $360^{\circ}$ [9], using settings to give a pull time around 25 s. NOTE: We use settings similar to those used for Vicia and tobacco guard cells [34], but with the coil heat elevated to give pull times roughly 25\% less than used for Vicia guard cells. The resulting microelectrodes have 1.8-2.0 cm-long shanks and tips that tapered with a $1-1.5^{\circ}$ angle (Figure $2 \mathrm{~A}$ ).

3. Store microelectrodes in a glass desiccator and coat microelectrodes with paraffin before impalement for reducing capacitance $[8,9,12]$.

\section{Key steps for impaling Arabidopsis guard cells}

\section{Before starting}

Electrical recordings using double-barrelled microelectrodes are carried out largely as described previously $[12,35]$ with some modifications. For $\mathrm{K}^{+}$currents, microelectrode barrels are filled with $200 \mathrm{mM} \mathrm{K}{ }^{+}$-Acetate, $\mathrm{pH}$ 7.5 , to minimise interference from the anion current and recordings are carried out in continuously-flowing RB1; for measurements of anion current, both electrode barrels are filled with $200 \mathrm{mM} \mathrm{CsCl}$ and the cells bathed in flowing RB2. Currents recorded under voltage clamp are normalised to the surface area of the impaled guard cells and, for $\mathrm{K}^{+}$channel analysis, are corrected for background (instantaneous) currents as described previously [12,35] using Henry's EP suite software (Y-Science, University of Glasgow, UK). NOTE: The typical length and radius of Arabidopsis guard cells are 20 and $5 \mu \mathrm{m}$, respectively. For the data summarised in the Tables, these parameters were $22 \pm 0.6 \mu^{2}$ and $4 \pm 0.1 \mu \mathrm{m}$, respectively. Assuming a spheroid geometry, the mean guard cell surface area and volume were $468 \pm 12 \mu \mathrm{m}^{2}$ and $783 \pm 21 \mu \mathrm{m}^{3}$, respectively.

An essential prerequisite is the use of a stable microelectrode mount that can accommodate two amplifier headstages and halfcells with a minimum of mechanical relaxation over time. We have adapted a Huxley-type micromanipulator with a custom-machined aluminium brace that supports positioning clamps (Narashige, C2-type)

Table 2 Effect of pre-treatment with opening buffer (OB) on seal lasting time of guard cells from all Arabidopsis lines Col-0, nia1nia2, QC3, QL3, kC1-3, syp121, syp1210x, and dhar1-3

\begin{tabular}{|c|c|c|c|c|c|c|c|c|}
\hline & Average of 8 & lines & Col-0 & & nia1nia2 & & QC3 & \\
\hline Time (min) & Control & Pretreatment & Control & Pretreatment & Control & Pretreatment & Control & Pretreatment \\
\hline $\mathrm{I}_{\mathrm{K}} \mu \mathrm{A} \mathrm{cm}^{-2}$ experiments & $21.2 \pm 4.0(179)$ & $34.4 \pm 3.8^{* *}(49)$ & $19.2 \pm 1.5(72)$ & $36.8 \pm 3.1^{* *}(14)$ & $18.6 \pm 2.6(7)$ & $33.7 \pm 2.7^{*}(34)$ & $28.8 \pm 3.6(45)$ & $40.0 \pm 6.8^{*}(12)$ \\
\hline$I_{\text {anion }} \mu \mathrm{A} \mathrm{cm}^{-2}$ experiments & $19.1 \pm 3.6(45)$ & $35.0 \pm 4.6^{* *}(29)$ & $19.1 \pm 3.2(12)$ & $28.3 \pm 4.9^{*}(9)$ & $17.0 \pm 3.5(15)$ & $37.5 \pm 5.2^{* *}(12)$ & $22.7 \pm 3.2(13)$ & $52.0 \pm 14.2^{* *}(5)$ \\
\hline
\end{tabular}

All the experiments lasted less than $10 \mathrm{~min}$ are discarded. Data are means $\pm \mathrm{SE}$ of $(\mathrm{n})$ experiments.

* $\mathrm{P}<0.05$; ${ }^{*} \mathrm{P}<0.01$ as compared with control. 
Table 3 Analysis of maximal conductance $\left(g_{\max }\right)$, gating charge $(\delta)$, half maximal voltage $\left(V_{1 / 2}\right)$ of $I_{K, \text { in }}$ and $I_{K, \text { out }}$ for the Arabidopsis lines Col-0, nia1nia2, QC3, QL3, kc1-3, syp121, syp121ox, and dhar1-3 in both opening and non-condition

\begin{tabular}{|c|c|c|c|c|c|c|c|c|c|}
\hline \multirow[t]{2}{*}{ Channel } & \multirow[t]{2}{*}{ Parameters } & \multicolumn{2}{|c|}{ Average of 8 lines } & \multicolumn{2}{|c|}{ Col-0 } & \multicolumn{2}{|c|}{ nia1nia2 } & \multicolumn{2}{|c|}{ QC3 } \\
\hline & & Control & Pretreatment & Control & Pretreatment & Control & Pretreatment & Control & Pretreatment \\
\hline \multirow[t]{3}{*}{$\left.\right|_{K, \text { in }}$} & $g_{\max }\left(\mathrm{mS} \mathrm{cm}^{-2}\right)$ & $2.3 \pm 0.1(103)$ & $2.0 \pm 0.2(67)$ & $2.2 \pm 0.2(26)$ & $2.6 \pm 0.2^{*}(15)$ & $0.3 \pm 0.1(10)$ & $0.9 \pm 0.1^{* *}(36)$ & $3.4 \pm 0.3(21)$ & $3.2 \pm 0.2(13)$ \\
\hline & $\delta$ & $2.2 \pm 0.1(103)$ & $1.9 \pm 0.1^{*}(67)$ & $2.4 \pm 0.1(26)$ & $2.0 \pm 0.1 *(15)$ & $1.1 \pm 0.2(10)$ & $1.9 \pm 0.1^{* *}(36)$ & $2.1 \pm 0.2(21)$ & $1.9 \pm 0.2(13)$ \\
\hline & $\mathrm{V}_{1 / 2}(\mathrm{mV})$ & $-186 \pm 2.1(103)$ & $-182 \pm 1.6(67)$ & $-185 \pm 3(26)$ & $-182 \pm 2(15)$ & $-180 \pm 10(10)$ & $-179 \pm 2.5(36)$ & $-185 \pm 4.3(21)$ & $188 \pm 2.6(13)$ \\
\hline \multirow[t]{3}{*}{$\left.\right|_{k, \text { out }}$} & $\mathrm{g}_{\max }\left(\mathrm{mS} \mathrm{cm} \mathrm{cm}^{-2}\right)$ & $3.0 \pm 0.1(103)$ & $3.5 \pm 0.1 *(67)$ & $2.6 \pm 0.2(26)$ & $3.8 \pm 0.6^{* *}(15)$ & $2.7 \pm 0.3(10)$ & $3.6 \pm 0.2 *(36)$ & $3.9 \pm 0.3(21)$ & $3.5 \pm 0.3(13)$ \\
\hline & $\delta$ & $1.6 \pm 0.1(103)$ & $1.6 \pm 0.1(67)$ & $1.8 \pm 0.1(26)$ & $1.6 \pm 0.1(15)$ & $1.5 \pm 0.1(10)$ & $1.5 \pm 0.1(36)$ & $1.5 \pm 0.2(21)$ & $1.5 \pm 0.2(13)$ \\
\hline & $\mathrm{V}_{1 / 2}(\mathrm{mV})$ & $0.9 \pm 1.7(103)$ & $-3.6 \pm 1.7(67)$ & $6.0 \pm 2.6(26)$ & $0.4 \pm 2.3(15)$ & $-10 \pm 4.6(10)$ & $-2.4 \pm 2.4(36)$ & $-4.1 \pm 4.1(21)$ & $-6.5 \pm 5.7(13)$ \\
\hline
\end{tabular}

Data are means \pm SE of ( $\mathrm{n}$ ) experiments.

${ }^{*} \mathrm{P}<0.05 ;{ }^{* *} \mathrm{P}<0.01$ as compared with control.

to stabilise paired amplifier headstages (Figure 2). Additionally, connections between the headstages and microelectrode barrels are made using $\mathrm{Ag}-\mathrm{AgCl} \mid \mathrm{KCl}$ halfcells similar to those described previously [9], but constructed around the light-weight polypropylene tubing from the tips of disposable 2-ml pipettes, which is essential to provide mechanical stability for long-term recordings (Figure 2).

1. Carry out impalement by first positioning the microelectrode to rest over one guard cell and present the tip across the stomatal pore before advancing along the axis of the microelectrode to impale the second guard cell. NOTE: The initial movement of the microelectrode towards the guard cell requires very gentle manipulation. A 'snapping' of the tip through the cell wall and into the guard cell should occur together with an increase in input resistance to approximately $1 \mathrm{G} \Omega$ and decrease (more negative) in membrane potential (see Additional file 1: Table S1).

2. Wait 2-3 min for a seal to stabilize after impalement. NOTE: As with Vicia guard cells [34], successful impalements show an increase in input resistance and membrane voltage over 2-3 minutes. Impalements carried out in RB1 buffer, but with $0.1 \mathrm{mM} \mathrm{KCl}$, will give much larger changes in voltage as the microelectrode seals into the cell. For purposes of the comparisons below, we allowed recordings to stabilise under free-running conditions for 10 minutes before collecting voltage clamp data.

3. Switch to the RB1 or RB2 for $\mathrm{K}^{+}$and anion currents measurements, respectively, using a gravity-fed system.

\section{Comments}

Buffer pretreatment and recording stability

Impalements are easier to achieve, and can be held for longer time when epidermal peels are pretreated with OB similar to that used by Allen et al. [36]. For comparison, the data in Tables 1, 2, 3, 4 and Additional file 1: Table S1 summarise measurements from the guard cells of 407 stomata, including measurements of stomatal aperture, free-running membrane voltage, inward- and outward-rectifying $\mathrm{K}^{+}$currents, $\mathrm{I}_{\mathrm{K} \text {,in }}$ and $\mathrm{I}_{\mathrm{K} \text {,out }}$, respectively, and in separate experiments of anion current, $\mathrm{I}_{\text {anion }}$. The data sets include measurements with and without OB pretreatment and show that stomata across all the lines tested were significantly more open $(\mathrm{P}<0.05)$ following $\mathrm{OB}$ pretreatment: mean apertures following $\mathrm{OB}$ treatments were $3.22 \pm 0.09$ and $3.48 \pm 0.09 \mu \mathrm{m}$ at the start of measurements in RB1 and RB2, respectively, compared to $2.95 \pm 0.04$ and $2.89 \pm 0.06 \mu \mathrm{m}$ without $\mathrm{OB}$ pretreatment (see Table 1). Most important, the comparison shows that OB pretreatment greatly extends the time over which impalements can be held. Stable current recordings were extended by $62 \%$ and $83 \%$ for $\mathrm{K}^{+}$and anion current studies, respectively

Table 4 Effect of pre-treatment with opening buffer (OB) on the 'rundown' of $I_{K, \text { in }}$ and $I_{K, \text { out }}$ in Arabidopsis guard cells of Col-0, nia1nia2 and QC3

\begin{tabular}{|c|c|c|c|c|c|c|c|}
\hline \multirow[t]{2}{*}{ Channel } & \multirow{2}{*}{$\begin{array}{l}\text { Current } \\
\left(\mu \mathrm{A} \mathrm{cm}{ }^{-2}\right)\end{array}$} & \multicolumn{2}{|c|}{ Col-0 } & \multicolumn{2}{|c|}{ nia1nia2 } & \multicolumn{2}{|c|}{ QC3 } \\
\hline & & $10 \mathrm{~min}$ & $30 \mathrm{~min}$ & $10 \mathrm{~min}$ & $30 \mathrm{~min}$ & $10 \mathrm{~min}$ & $30 \mathrm{~min}$ \\
\hline \multirow[t]{2}{*}{$I_{K, \text { in }}$} & Control & $-484.1 \pm 185.6$ & $-6.43 \pm 3.3^{* *}$ & $-118.7 \pm 30.2$ & $-1.2 \pm 10.3^{* *}$ & $-413.8 \pm 142.1$ & $-8.1 \pm 0.3^{* *}$ \\
\hline & Pretreatment & $-586.3 \pm 40.7$ & $-431.9 \pm 75.2$ & $-223.0 \pm 49.5$ & $-247.1 \pm 54.8$ & $-602.1 \pm 112.4$ & $-543.2 \pm 44.3$ \\
\hline \multirow[t]{2}{*}{$\mathrm{I}_{\mathrm{K}, \text { out }}$} & Control & $598.2 \pm 89.0$ & $145.29 \pm 36.0^{* *}$ & $527.9 \pm 90.1$ & $71.2 \pm 10.4^{* *}$ & $591.2 \pm 111.1$ & $168.4 \pm 119.5^{* *}$ \\
\hline & Prereatment & $901.0 \pm 271.5$ & $921.64 \pm 236.4$ & $698.8 \pm 147.2$ & $669.9 \pm 174.9$ & $741.3 \pm 198.8$ & $732.3 \pm 127.0$ \\
\hline
\end{tabular}

Data are means \pm SE from the analysis of $>5$ experiments extending over $60 \mathrm{~min}$ or more in each case.

${ }^{* *} \mathrm{P}<0.01$ as compared with control. 


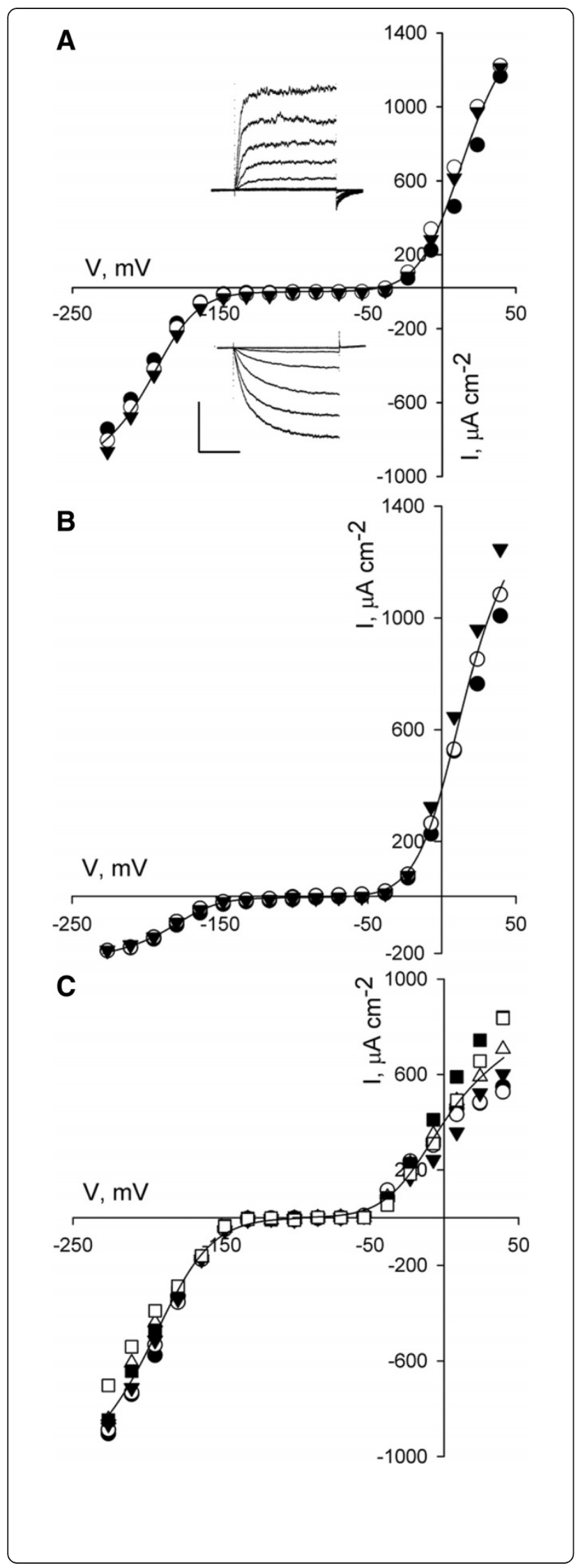

Figure $3 \mathrm{I}_{\mathrm{K} \text {,in }}$ and $\mathrm{I}_{\mathrm{K} \text { out }}$ of wild-type (A), nia1nia2 (B), and QC3 (C) mutant Arabidopsis guard cells following pretreatment with opening buffer (OB). (A) Steady-state current-voltage curves for $I_{k}$, in and $I_{k, o u t}$ from one guard cell of wild-type Arabidopsis recorded at intervals over 30 min after 2-h OB pretreatment. Shown are data for voltage clamp scans taken at 10 (closed circles), 20 (open circles), and 30 min (closed triangles) after impalement. Clamp scans were from a holding voltage of $-100 \mathrm{mV}$ with tail steps to $-100 \mathrm{mV}$. Test voltage steps were to voltages between -80 and $+50 \mathrm{mV}$ for $\mathrm{I}_{\mathrm{K} \text {,out }}$ and to voltages between -100 and $-240 \mathrm{mV}$ for $\mathrm{I}_{\mathrm{k} \text {,in }}$. Currentvoltage curves were fitted jointly to a Boltzmann function (solid lines) and yielding values for $g_{\max }$ of 3.8 and $6.3 \mu S \mathrm{~cm}^{-2}, V_{1 / 2}$, of -181 and $+1 \mathrm{mV}$, and $\delta$ of 1.9 and 1.8 for $I_{K, \text { in }}$ and $I_{k, o u t}$, respectively. Insets: Current traces for time points at $30 \mathrm{~min}$. Scale: $500 \mu \mathrm{A} \mathrm{cm}{ }^{-2}$ vertical, $2 \mathrm{~s}$ horizontal. (B) Steady-state current-voltage curves for $I_{k}$ in and $I_{k, \text { out }}$ from one guard cell of nialnia2 mutant Arabidopsis recorded at intervals over 30 min after 2-h OB pretreatment. Shown are data for voltage clamp scans taken at 10 (closed circles), 20 (open circles), and 30 min (closed triangles) after impalement. Clamp voltage scans as above. Current-voltage curves were fitted jointly to a Boltzmann function (solid lines) and yielding values for $g_{\max }$ of 0.9 and $6.1 \mu \mathrm{S} \mathrm{cm} \mathrm{cm}^{-2}, \mathrm{~V}_{1 / 2}$, of -178 and $+5 \mathrm{mV}$, and $\delta$, of 1.8 and 1.8 for $I_{K, \text { in }}$ and $I_{\text {Kout, }}$ respectively. (C) Steady-state current-voltage curves for $I_{K, \text { in }}$ and $I_{K, \text { out }}$ from one guard cell of nia1nia2 mutant Arabidopsis recorded at intervals over 60 min after 2-h OB pretreatment. Shown are data for voltage clamp scans taken at 10 (closed circles), 20 (open circles), and 30 (closed triangles) 40 (open triangles), 50 (closed squares) and 60 (open squares) min after impalement. Clamp voltage scans as above. Current-voltage curves were fitted jointly to a Boltzmann function (solid lines) and yielding values for $\mathrm{g}_{\max }$ of 4.1 and $4.6 \mu \mathrm{S} \mathrm{cm} \mathrm{cm}^{-2}, V_{1 / 2},-182$ and $-7 \mathrm{mV}$, and $\delta$, of 1.7 and 1.9 for $\mathrm{I}_{\mathrm{K}, \mathrm{in}}$ and $I_{k, \text { out }}$, respectively. NOTE: Data analysis and curve fittings were carried out using SigmaPlot 11 (Systat Software, Inc., USA) and are reported, where appropriate, as means $\pm S E$ of $n$ observations. Where appropriate significance was determined using Students' T-test. Gating characteristics for $I_{K, \text { in }}$ and $I_{K, \text { out }}$ were determined by fitting steady-state current-voltage curves to Eqn. (1) using non-linear, least-squares minimisation and the Marquardt-Levenberg algorithm [39].

- to periods often in excess of one hour - compared with experiments in which guard cells were impaled immediately after peeling and mounting (see Table 2). The capacity to extend electrical recordings over this time scale ensures that experimental challenges such as exposures to hormones and different environmental parameters (for example $\mathrm{CO}_{2}$, light, $\mathrm{Ca}^{2+}$ and other ion concentrations) can be carried out on a cell-by-cell basis in Arabidopsis guard cells much as was pioneered in guard cells of Vicia and tobacco $[12,13,35,37,38]$. In effect, work over these timescales enables the use of each cell as its own control. The following summaries are provided in conjunction with the tabulated data.

\section{$\mathrm{K}^{+}$channel currents}

Out of 275 independent experiments with measurements of the $\mathrm{K}^{+}$currents $88 \%$ showed $\mathrm{I}_{\mathrm{K} \text {,in }}$ activity and $100 \%$ yielded $\mathrm{I}_{\mathrm{K} \text {,out }}$ activity as judged by the current activation kinetics, voltage dependencies and block by $\mathrm{Cs}^{+}$and $\mathrm{TEA}^{+}$(not shown, see Roelfsema and Prins 


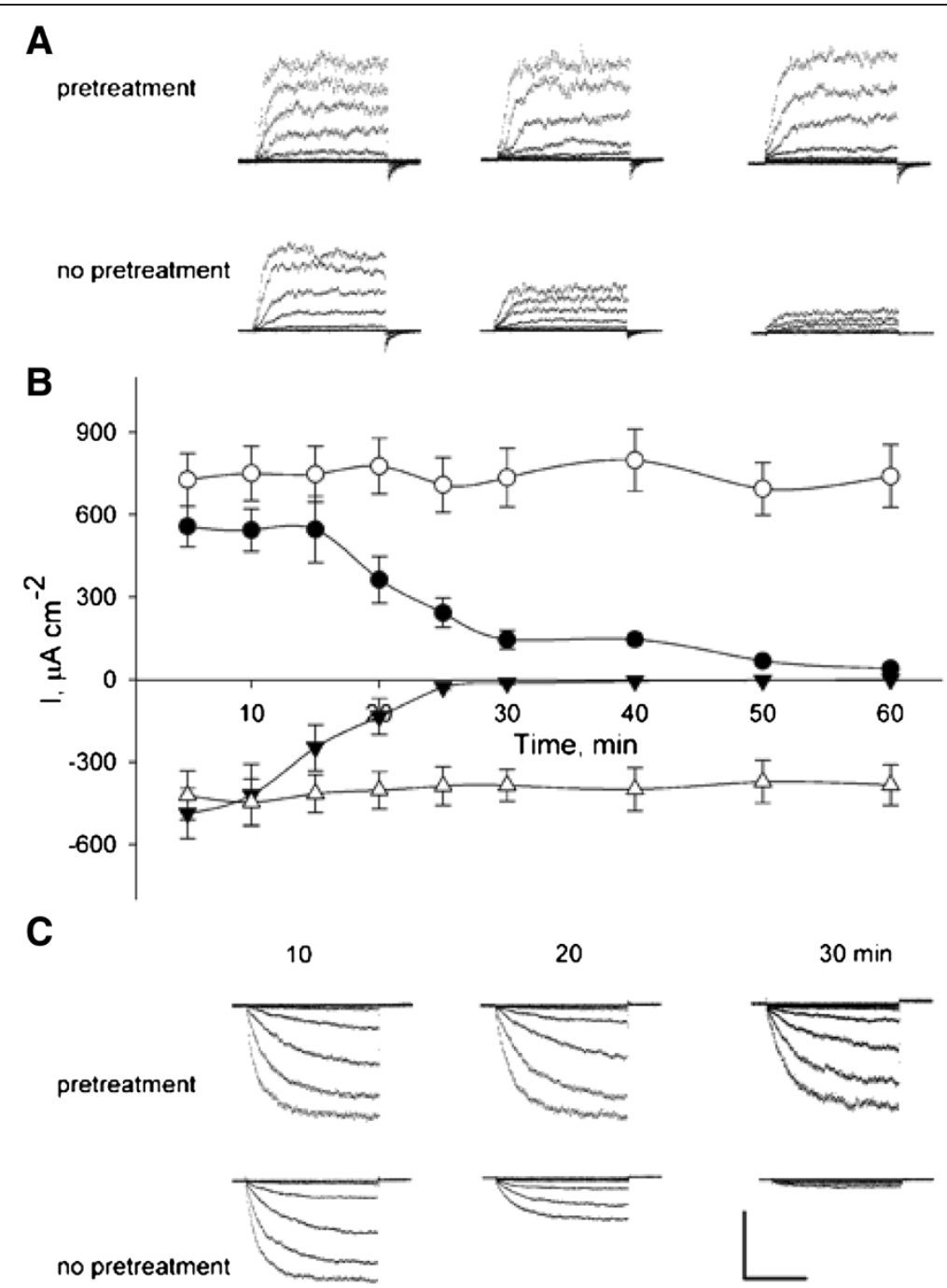

Figure 4 Decay in $\mathrm{I}_{\mathrm{K}, \text { in }}$ and $\mathrm{I}_{\mathrm{K} \text {,out }}$ from guard cells of wild-type Arabidopsis plants without (no pretreatment) and with opening buffer pretreatment (pretreatment)Decay in $I_{K, \text { in }}$ and $I_{K, \text { out }}$ from guard cells of wild-type Arabidopsis plants without (no pretreatment) and with opening buffer pretreatment (pretreatment). Voltage clamp scans were carried out at intervals following impalements. Raw current traces are shown in for scans at 10, 20, and 30 min time points from two guard cells for $I_{k, \text { out }}(\mathbf{A})$ and $I_{k, \text { in }}(\mathbf{C})$. Scale: vertical, $500 \mu \mathrm{A} \mathrm{cm}{ }^{-2}$; horizontal, $2 \mathrm{~s}$. Clamp scans were from a holding voltage of $-100 \mathrm{mV}$ with tail steps to $-100 \mathrm{mV}$. Test voltage steps were to voltages between -80 and $+50 \mathrm{mV}$ for $\mathrm{I}_{\mathrm{k}, \mathrm{out}}$ and to voltages between -100 and $-240 \mathrm{mV}$ for $\mathrm{I}_{\mathrm{k}, \mathrm{n}}$. Data in (B) summarise the two current amplitude means $\pm \mathrm{SE}$ (filled circles, no pretreatment; open circles, pretreatment) from 12 independent experiments with $I_{k, \text { out }}$ determined at $+40 \mathrm{mV}$ and $I_{\mathrm{K}, \text { in }}$ determined at $-220 \mathrm{mV}$. Note that currents recorded from guard cells in control experiments without OB pretreatment generally decayed with halftimes of $15-20 \mathrm{~min}$

[26,27], Forestier et al. [28] and Blatt et al. [38]). Guard cells pretreated with OB showed appreciably greater stability in both $\mathrm{I}_{\mathrm{K}, \text { in }}$ and $\mathrm{I}_{\mathrm{K} \text {,out }}$ over extended time periods compared with guard cells impaled without pretreatment (Figures 3, 4 and Tables 3 and 4). Mean $\mathrm{I}_{\mathrm{K} \text {,in }}$ and $\mathrm{I}_{\mathrm{K} \text {,out }}$ amplitudes of all of the lines tested at $30 \mathrm{~min}$, for example, decayed to less than $2 \%$ and $22 \%$, respectively, of the initial amplitudes recorded $10 \mathrm{~min}$ after impalements in guard cells without OB pretreatment (see also [26]). By contrast, the $\mathrm{K}^{+}$currents showed less than a 5\% change in amplitude over the same time period when guard cells were first pretreated in $\mathrm{OB}$.
For quantitative comparisons, the steady-state kinetic characteristics for the $\mathrm{K}^{+}$currents were fitted either individually or jointly to a Boltzmann function of the form

$$
I=\frac{g_{\max }\left(V-E_{K}\right)}{\left(1+\exp \left(-\delta\left(V_{1 / 2}-V\right) F / R T\right)\right.}
$$

where $E_{K}$ is the equilibrium voltage for $\mathrm{K}^{+}$across the membrane, $g_{\max }$ is the maximum ensemble conductance for the channels, $\delta$ is the voltage sensitivity coefficient or gating charge and $V_{1 / 2}$ is the voltage at 


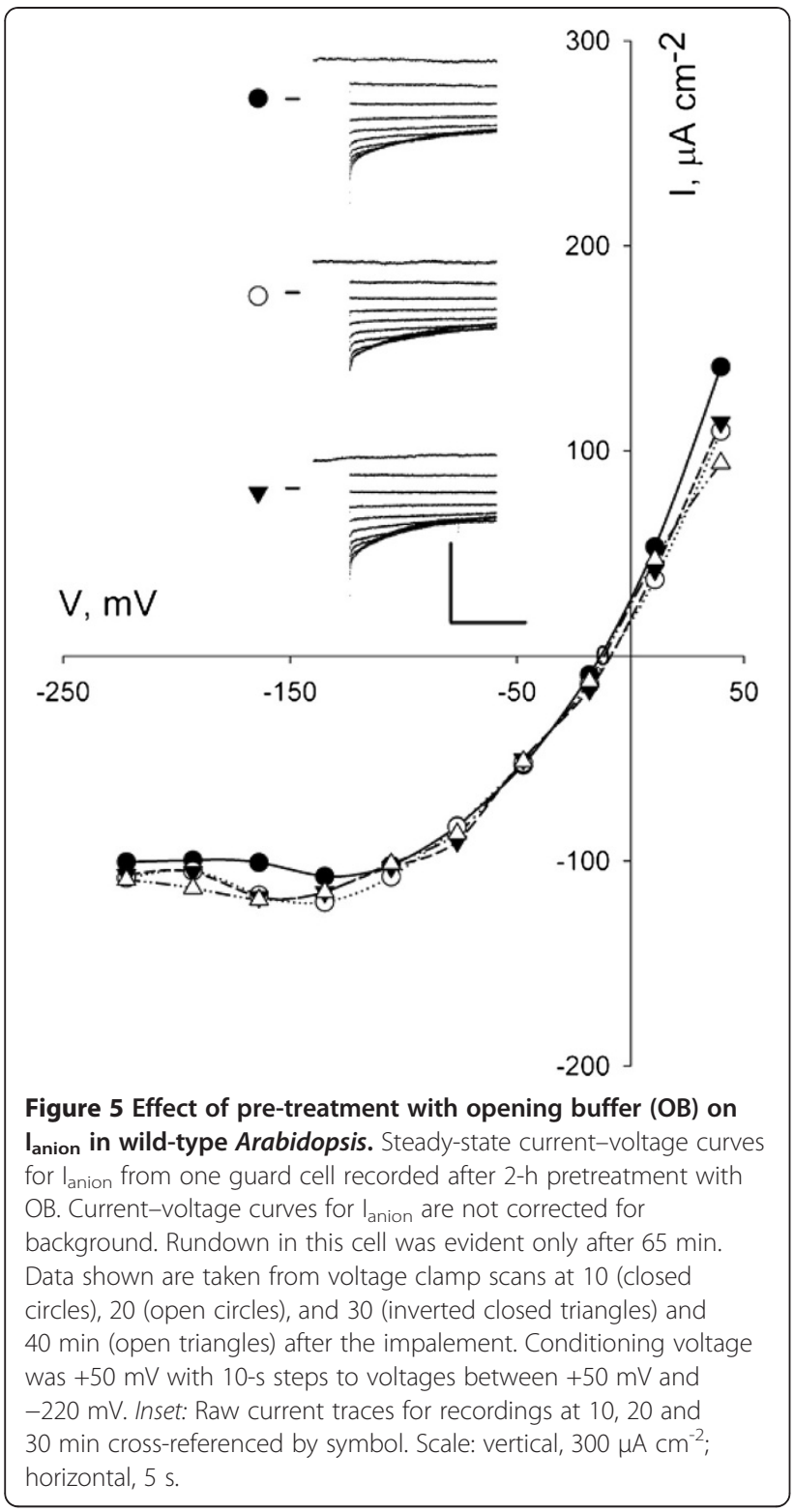

which the ensemble conductance equals $g_{\max } / 2$. Both approaches yielded parameter values that are statistically indistinguishable (Table 3) and are similar to those obtained previously for Arabidopsis as well as Vicia and tobacco guard cells [13,24,26-28,37,40].

Comparisons of the intrinsic gating characteristics for the different Arabidopsis lines and the overall means showed that OB pretreatment had no substantive effect on either $\delta$ or $V_{1 / 2}$ (see also Figure 3). Values for $g_{\max }$ for $I_{K, \text { out }}$ showed a significant increase in both the wildtype and nia1nia2 mutant lines, whereas $\mathrm{g}_{\max }$ was largely unaffected in the QC3 mutant line (Table 3). These activities were reflected also in differences in the free-running membrane voltages (see Additional file 1:
Table S1). We note, too, a close similarity in the gating parameters $\delta$ and $V_{1 / 2}$ between all of the lines, with the exception of the syp121 and nia1nia2 mutants for which the genetic deletions are expected to affect channel gating or $\mathrm{K}^{+}$nutrition and balance [31]. Overall, these results confirm that the underlying gating properties for the two classes of $\mathrm{K}^{+}$channels were unaffected, at least during the first hour after impalements.

\section{Anion current}

To date, only Forestier et al. [28] reported $\mathrm{I}_{\text {anion }}$ in intact Arabidopsis stomatal guard cells, although components of $\mathrm{I}_{\text {anion }}$ have been identified with the SLAC1 and ALMT12 gene products [41-44]. We recorded $\mathrm{I}_{\text {anion }}$ in over $95 \%$ of cases from 158 guard cells in RB2 with current similar to past measurements from Arabidopsis, Vicia and tobacco $[28,35,40]$. The mean membrane voltage of $-9.9 \pm 1.6 \mathrm{mV}$ in $\mathrm{RB} 2$ was also comparable to those recorded in these previous studies. We found no appreciable difference between guard cells with or without $\mathrm{OB}$ pretreatment (Additonal file 1: Table S1) but, again, pretreatment prolonged the timeframe for $\mathrm{I}_{\text {anion }}$ recordings and experiments frequently extended over periods of one hour (Table 2 and Figure 5). Thus OB pretreatment improved the stability of $\mathrm{I}_{\text {anion }}$ recordings much as it did for those of $\mathrm{I}_{\mathrm{K}, \text { in }}$ and $\mathrm{I}_{\mathrm{K}, \text { out }}$.

\section{Summary}

Three key factors are essential for successful, two-electrode, voltage clamp recordings with Arabidopsis guard cells. First, the preparation and handling of the plants is important, incorporating a pretreatment regime with a stomatal opening buffer prior to the start of experiments; second, microelectrode design must meet the demands for impalements of very small cells, notably in the use of fine tips with input resistances roughly 5-fold higher than typically used for Vicia and tobacco guard cells; finally, a modified clamp and brace to carry the amplifier headstages and construction of light-weight, but rigid halfcells are essential prerequisites to provide stability without mechanical relaxation for long-term recordings. Overall, this combination of factors is sufficient to achieve measurements comparable to those with the much larger guard cells of Vicia and tobacco. These methods should now greatly speed the analysis of many mutants of Arabidopsis by simplifying electrophysiological studies of the guard cells.

\section{Additional file}

Additional file 1: Table S1. Effect of pre-treatment with opening buffer (OB) on guard cell membrane potential $\left(E_{m}\right)$ in all Arabidopsis lines Col-0, nialnia2, QC3, QL3, kC1-3, syp121, syp1210x, and dhar1-3. Data are means \pm SE of $(n)$ experiments. 


\section{Authors' contributions}

ZHC carried out the electrophysiological studies and analysed the data together with XQX; CE carried out aperture measurements and image analysis; $\mathrm{AH}$ and MRB developed the software utilities, mechanical and electrical hardware for the voltage clamp recordings; ZHC, CE and MRB wrote the manuscript. All authors read and approved the final manuscript.

\section{Acknowledgements}

We thank Amparo Ruiz-Prado for growth room support. This work was funded by grants BB/F001673/1, BB/F001630/1 and BB/I024496/1 to MRB from the UK Biotechnology and Biological Sciences Research Council. CE was supported initially by a Glasgow University Open PhD Scholarship and by a grant from Plant Biosciences Ltd, Norwich. ZHC was supported additionally by a 2011 UWS Research Travel Fellowship. Seed of the nia1nia2 and pyr1/ pyl1/pyr2/py/4 mutants were gifts from Prof. S. Neill in University of the West England and Prof. S. Cutler of University of California in Riverside, respectively.

\section{Author details}

${ }^{1}$ Laboratory of Plant Physiology and Biophysics, Institute of Molecular, Cell and Systems Biology, University of Glasgow, Glasgow G12 8QQ, UK. ${ }^{2}$ School of Science and Health, University of Western Sydney, Richmond NSW 2753, Australia.

Received: 13 August 2011 Accepted: 10 April 2012

Published: 6 May 2012

\section{References}

1. Willmer C, Fricker MD: Stomata. London: Champman and Hall; 1996.

2. Raven J: Selection pressures on stomatal evolution. New Phytol 2002 153:371-386

3. Hetherington AM, Woodward Fl: The role of stomata in sensing and driving environmental change. Nature 2003, 424:901-908.

4. Blatt MR: Cellular signaling and volume control in stomatal movements in plants. Ann Rev Cell Dev Biol 2000, 16:221-241.

5. Schroeder Jl, Allen GJ, Hugouvieux V, Kwak JM, Waner D: Guard cell signal transduction. Annu Rev Plant Physiol Plant Mol Biol 2001, 52:627-658.

6. Blatt MR, Garcia-Mata C, Sokolovski S: Membrane transport and $\mathrm{Ca}^{2+}$ oscillations in guard cells. In Rhythms in Plants. Edited by Mancuso S, Shabala S. Berlin: Springer; 2007

7. Dodd AN, Love J, Webb AAR: The plant clock shows its metal: circadian regulation of cytosolic free $\mathrm{Ca}^{2+}$. Trends Plant Sci 2005, 10:15-21.

8. Blatt MR: Concepts and techniques in plant membrane physiology. In Membrane Transport in Plants. Edited by Blatt M. Oxford: Blackwell; 2004.

9. Blatt MR: A Primer in Plant Electrophysiological Methods. In Methods in Plant Biochemistry. Edited by Hostettmann K. London: Academic; 1991.

10. Jack JJB, Noble D, Tsien RW: Electric Current Flow in Excitable Cells. Oxford: Clarendon; 1983

11. Blatt MR: Electrical characteristics of stomatal guard cells: the contribution of ATP-dependent, "electrogenic" transport revealed by current-voltage and difference-current-voltage analysis. J Membr Biol 1987, 98:257-274

12. Blatt $\mathrm{MR}$, Armstrong $\mathrm{F}: \mathrm{K}^{+}$channels of stomatal guard cells: abscisic acidevoked control of the outward rectifier mediated by cytoplasmic $\mathrm{pH}$. Planta 1993, 191:330-341.

13. Garcia-Mata C, Gay R, Sokolovski S, Hills A, Lamattina L, Blatt MR: Nitric oxide regulates $\mathrm{K}^{+}$and $\mathrm{Cl}^{-}$channels in guard cells through a subset of abscisic acid-evoked signaling pathways. Proc Natl Acad Sci USA 2003, 100:11116-11121.

14. Meharg AA, Blatt MR: Nitrate transport in root hairs of Arabidopsis thaliana: kinetic control by membrane voltage and $\mathrm{pH}$. J Membr Biol 1995, 145:49-66.

15. Chen ZH, Grefen C, Donald N, Hills A, Blatt MR: A bicistronic, Ubiquitin-10 promoter-based vector cassette for transient transformation and functional analysis of membrane transport demonstrates the utility of quantitative voltage clamp studies on intact Arabidopsis root epidermis. Plant Cell Environ 2011, 34:554-564.

16. Blatt MR, Slayman CL: Role of "active" potassium transport in the regulation of cytoplasmic $\mathrm{pH}$ by nonanimal cells. Proc Natl Acad Sci USA 1987, 84:2737-2741.
17. Blatt MR, Beilby MJ, Tester M: Voltage dependence of the Chara proton pump revealed by current-voltage measurement during rapid metabolic blockade with cyanide. J Membr Biol 1990, 114:205-223.

18. Neher E, Sakmann B: Single-channel currents recorded from the membrane of denervated frog muscle fibres. Nature 1976, 260:779-802.

19. Hamill OP, Marty A, Neher E, Sakmann B, Sigworth FJ: Improved patchclamp techniques for high-resolution current recording from cells and cell-free membrane patches. Pfluegers Archiv Eur J Physiol 1981, 391:85-100

20. White PJ, Biskup B, Elzenga JTM, Homann U, Thiel G, Wissing F, Maathuis FJM: Advanced patch-clamp techniques and single-channel analysis. J Exp Bot 1999, 50:1037-1054.

21. Spanswick RM: Electrical coupling between cells of higher plants - direct demonstration of intercellular communication. Planta 1972, 102:215-233.

22. Brudern A, Thiel G: Effect of cell-wall-digesting enzymes on physiological state and competence of maize coleoptile cells. Protoplasma 1999, 209:246-255.

23. Sutter JU, Sieben C, Hartel A, Eisenach C, Thiel G, Blatt MR: Abscisic acid triggers the endocytosis of the Arabidopsis KAT1 $\mathrm{K}^{+}$channel and its recycling to the plasma membrane. Curr Biol 2007, 17:1396-1402.

24. Perfus-Barbeoch L, Leonhardt N, Vavasseur A, Forestier C: Heavy metal toxicity: cadmium permeates through calcium channels and disturbs the plant water status. Plant J 2002, 32:539-548

25. Wille A, Lucas W: Ultrastructural and histochemical studies on guard cells. Planta 1984, 160:129-142.

26. Roelfsema MG, Prins HBA: Ion channels in guard cells of Arabidopsis thaliana (L) Heynh. Planta 1997, 202:18-27.

27. Roelfsema MG, Prins HBA: The membrane potential of Arabidopsis thaliana guard cells: depolarizations induced by apoplastic acidification. Planta 1998, 205:100-112.

28. Forestier C, Bouteau F, Leonhardt N, Vavasseur A: Pharmacological properties of slow anion currents in intact guard cells of Arabidopsis. Application of the discontinuous single-electrode voltage-clamp to different species. Pflugers Archiv Eur J Physiol 1998, 436:920-927.

29. Wilkinson JQ, Crawford NM: Identification and characterisation of a chlorate-resistant mutant of Arabidopsis thaliana with mutations in both nitrate reductase structural genes NIA1 and NIA2. Mol Gen Genet 1993, 239:289-297.

30. Park SY, Fung P, Nishimura N, Jensen DR, Fujii H, Zhao Y, Lumba S, Santiago J, Rodrigues A, Chow TFF, et al: Abscisic Acid Inhibits Type 2C Protein Phosphatases via the PYR/PYL Family of START Proteins. Science 2009, 324:1068-1071.

31. Honsbein A, Sokolovski S, Grefen C, Campanoni P, Pratelli R, Paneque M, Chen ZH, Johansson I, Blatt MR: A Tripartite SNARE- $\mathrm{K}^{+}$Channel Complex Mediates in Channel-Dependent $\mathrm{K}^{+}$Nutrition in Arabidopsis. Plant Cell 2009, 21:2859-2877.

32. Pajonk S, Kwon C, Clemens N, Panstruga R, Schulze-Lefert P: Activity determinants and functional specialization of Arabidopsis PEN1 syntaxin in innate immunity. J Biol Chem 2008, 283:26974-26984.

33. Chen Z, Gallie DR: The ascorbic acid redox state controls guard cell signaling and stomatal movement. Plant Cell 2004, 16:1143-1162.

34. Blatt M: Electrical characteristics of stomatal guard cells: the ionic basis of the membrane potential and the consequence of potassium chloride leakage from microelectrodes. Planta 1987, 170:272-287.

35. Chen ZH, Hills A, Lim CK, Blatt MR: Dynamic regulation of guard cell anion channels by cytosolic free $\mathrm{Ca}^{2+}$ concentration and protein phosphorylation. Plant J 2010, 61:816-825.

36. Allen GJ, Chu SP, Harrington CL, Schumacher K, Hoffman T, Tang YY, Grill E, Schroeder JI: A defined range of guard cell calcium oscillation parameters encodes stomatal movements. Nature 2001, 411:1053-1057.

37. Leyman B, Geelen D, Quintero FJ, Blatt MR: A tobacco syntaxin with a role in hormonal control of guard cell ion channels. Science 1999, 283:537-540.

38. Blatt MR, Thiel G, Trentham DR: Reversible inactivation of $\mathrm{K}^{+}$channels of Vicia stomatal guard cells following the photolysis of caged inosito 1,4,5- trisphosphate. Nature 1990, 346:766-769.

39. Marquardt D: An algorithm for least-squares estimation of nonlinea parameters. J Soc Ind Appl Math 1963, 11:431-441. 
40. Grabov A, Leung J, Giraudat J, Blatt MR: Alteration of anion channel kinetics in wild-type and abi1-1 transgenic Nicotiana benthamiana guard cells by abscisic acid. Plant J 1997, 12:203-213.

41. Negi J, Matsuda O, Nagasawa T, Oba Y, Takahashi H, Kawai-Yamada M, Uchimiya $\mathrm{H}$, Hashimoto $\mathrm{M}$, Iba K: $\mathrm{CO}_{2}$ regulator SLAC1 and its homologues are essential for anion homeostasis in plant cells. Nature 2008, 452:483-486.

42. Vahisalu T, Kollist H, Wang YF, Nishimura N, Chan WY, Valerio G, Lamminmaki A, Brosche M, Moldau H, Desikan R, et al: SLAC1 is required for plant guard cell S-type anion channel function in stomatal signalling. Nature 2008, 452:487-491.

43. Meyer S, Mumm P, Imes D, Endler A, Weder B, Al-Rasheid KAS, Geiger D, Marten I, Martinoia E, Hedrich R: AtALMT12 represents an R-type anion channel required for stomatal movement in Arabidopsis guard cells. Plant J 2010, 63:1054-1062.

44. Sasaki T, Mori IC, Furuichi T, Munemasa M, Toyooka K, Matsuoka K, Yamamoto Y: Closing plant stomata requires a homolog of an Aluminum activated malate transporter. Plant Cell Physiol 2010, 51:354-365.

doi:10.1186/1746-4811-8-15

Cite this article as: Chen et al:: Protocol: optimised electrophyiological analysis of intact guard cells from Arabidopsis. Plant Methods 2012 8:15.

\section{Submit your next manuscript to BioMed Central and take full advantage of:}

- Convenient online submission

- Thorough peer review

- No space constraints or color figure charges

- Immediate publication on acceptance

- Inclusion in PubMed, CAS, Scopus and Google Scholar

- Research which is freely available for redistribution 